\title{
Paradigmas, historiografia crítica e direito moderno
}

\author{
Antônio Carlos Wolkmer*
}

Sumário: 1.Questões paradigmáticas para se repensar a história; 2.Historiografia jurídica tradicional: natureza e função; 3.Novos marcos na historicidade do direito.

\section{Questões paradigmáticas para se repensar a história}

Examinar e problematizar as relações entre a História e o Direito reveste-se hoje da maior importância, principalmente quando se tem em conta a percepção da normatividade extraída de um determinado contexto histórico definido como experiência pretérita que conscientiza e liberta o presente. Naturalmente esta preocupação dissocia-se de uma historicidade do jurídico, marcada por toda uma tradição teórico-empírica assentada em proposições revestidas pela força da continuidade, previsibilidade; formalismo e linearidade. Mas, para se alcançar uma nova leitura histórica do fenômeno jurídico enquanto expressão de idéias, pensamento e instituições, faz-se necessário apurar uma distinção das especificidades inerentes a cada campo científico, do que seja História, do que seja Direito, bem como o sentido e a função de uma interpretação que se reveste do viés tradicional ou crítico.

Antes de tratar de questões relativas à vinculação mais direta da historiografia, historicidade e história ao Direito, passamos a considerar a História como área de investigação. com autonomia e características próprias. Neste sentido, a História pode ser visualizada como a sucessão temporal dos atos humancs dinamicamente relacionados com a natureza e

* Antonio Carlos Wolkmer é professor titular de "História das Instituições Jurídicas"nos cursos de graduação e pós-graduação em Direito na Universidade Federal de Santa Catarina. Doutor em Direito e membro efetivo do Instituto dos Advogados Brasileiros (RJ). Professor de "Metodologia Jurídica" do IBEJ/PR e pesquisador do CNPq.

R. Fac. Direito, Curitiba, a.28, n.28, 1994/95, p.55-67 
a sociedade. ${ }^{1}$ A História expressa a complexa manifestação da experiência humana, interagida no bojo de fatos, acontecimentos e instituições. O caráter mutável, imperfeito e relativo da experiência humana permite proceder múltiplas interpretações desta historicidade. Daí a formulação, ora de uma História oficial, descritiva e personalizada do passado, e que serve para justificar a totalidade do presente, ora da elaboração de uma História subjacente, alternativa e problematizante que serve para modificar/recriar a realidade vigente. A postura contrastante entre uma História tradicional e uma História "alternativa" é perfeitamente sentida por historiadores como Peter Burke, identificados com a "nova História". Utilizando-se de categorias advindas da Filosofia da Ciência (Thomas Kuhn) e da Escola dos Annales, Peter Burke observa que a percepção da inconsistência do paradigma tradicional foi motivada por uma ampla variedade de mudanças que levaram à redefinição dos conceitos, das fontes, do método e da interpretação da História escrita. ${ }^{2}$

A análise atenta leva o historiador inglês a indicar alguns pontọs essenciais que distinguem a "antiga" da "nova" História.

Primeiramente, há de se observar que a "nova" História começou a privilegiar toda a atividade humana, desde os mínimos detalhes, o trivial e o cotidiano. Tal preocupação explica um relativismo cultural que destrói as tradicionais hegemonias temáticas que distinguem acontecimentos que são importantes e merecem ser narrados e outros que devem ser postos de lado e esquecidos. Agora, "tudo tem uma História". ${ }^{3}$ Um segundo aspecto a considerar é que a "nova" História não se ocupa mais da narração de acontecimentos, mas, sobretudo, das mudanças estruturais com destaque para o social e o econômico. A terceira constatação é que a História convencional parte de uma perspectiva de cima, ou seja, tem destacado a obra dos "grandes homens, estadistas, generais ou ocasionalmente eclesiásticos. Ao resto da humanidade foi destinado um papel secundário no drama da história". 4

1 Cf. José Van Den Besselaar, Introdução aos Estudos Históricos, $3^{a}$ ed., São Paulo, Herder, 1970, p. 29; E. H. Carr, Que é História? Rio d Janeiro, Paz e Terra, 1976.

2 Cf. Peter Burke (org.), A Escrita da História: Novas Perspectivas, São Paulo, UNESP, 1993, p. 19-20.

3 Peter Burke, A Escrita..., op. cit. 11.

4 Peter Burke, A Escrita..., op. cit. 12-13. 
Trata-se agora de recuperar a experiência histórica das bases, das pessoas comuns e das mentalidades coletivas que aspiram as rupturas sociais. Um quarto ponto que cabe sublinhar é a obrigatoriedade de se redefinir as fontes, ainda muito presas aos registros oficiais e aos documentos preservados em arquivos, buscando outros tipos de evidências confiáveis. Além da crítica que pode ser feita ao modelo tradicional de interpretação e explicação histórica, Burke assevera, por último, a presunção do paradigma tradicional em se ater a uma suposta objetividade dos fatos que não existe, pois a realidade é sempre visualizada através de representações, preconceitos e estereótipos. ${ }^{5}$

Essa distinção entre uma "antiga" e uma "nova" História, introduzida por Peter Burke, permite-nos aprofundar a incursão no sentido de se ter presente a inadequação de um modelo teórico tradicional e a consciência do rompimento, estabelecendo com clareza que tipo de perspectiva histórica se rejeita radicalmente e que espécie de historicidade se busca. Não mais uma História de justificações do passado, mas de transgressões e rupturas com relação ao presente.

Daí resulta, no desafio apontado por José Honório Rodrigues, quando interpreta a história da cultura e da sociedade brasileira, ou seja, a recuperação de um outro tipo de historicidade comprometida com a transformação do mundo, e com a salvação do próprio homem. ${ }^{6}$ É a recusa por uma historicidade identificada com a verdade dominante, oficial, arcaica e colonizada, e a opção por uma História "criadora e militante, que combate pela renovação e transformação constante do mundo, sua melhoria, sua paz, sua justiça. A História está indissoluvelmente ligada à consciência, o que nos leva, ou deve levar, a agir de modo histórico-político. O passado não deve ser estudado como um objeto morto, como uma ruína, nem como uma fonte de autoridade, mas como uma experiência apreendida e consolidada". ${ }^{7}$ A partir de uma interpretação das raízes históricas de nosso passado, José Honório Rodrigues utiliza-se da História como uma ciência instrumental que critica a realidade presente, assumindo um papel de sub-

5 Cf. Peter Burke, A Escrita..., op. cit., p. 14-15.

6 José Honório Rodrigues, Filosofia e História, Rio de Janeiro, Nova Fronteira, 1981, p. 29.

7 José Honório Rodrigues, Filosofia e..., op. cit., p. 30.

R. Fac. Direito, Curitiba, a.28, n.28, 1994/95, p.55-67 
versão ao cenário de opressão, manipulação e dependência. Tenta demonstrar em seus estudos históricos a missão política do historiador, que não pode ser de omissão e alheamento aos acontecimentos da realidade presente, mas de um agente de motivação no sentido de contribuir para a capacidade do povo fazer sua própria história. Esse engajamento do historiador implica também na reinterpretação das fontes do passado, na redefinição da pesquisa historiográfica e na reordenação metodológica. ${ }^{8}$

A mesma preocupação por uma História crítica e flexível é defendida por A. Vivar Flores quando busca o marco de referência teórica para embasar uma proposta de libertação latino-americana. Até hoje fez-se uma interpretação elitista da História, impondo-se, como aclama Leonardo Boff (citado por A. Vivar Flores), a "História dos que triunfaram, dos que chegaram ao poder. Não é a história dos vencidos, dos humilhados e ofendidos. Estes são esquecidos". ${ }^{9}$

Há que se fazer uma releitura da História de nosso continente periférico, processo este que implica em "recuperar a verdadeira história da América Latina, feita pelo homem latino-americano, até agora silenciado pela 'história oficial', sustentada pelos grupos de poder de dentro e de fora do território latino-americano". 10

Esses subsídios oferecidos por cientistas sociais, como P. Burke, J. H. Rodrigues e A. V. Flores, possibilitam-nos repensar o campo da História dentro de uma nova perspectiva metodológica, bem como sua aproximação e interação com o fenômeno jurídico sob o viés crítico-desmistificador.

\section{Historiografia Jurídica Tradicional: Natureza e Função}

$\mathrm{Na}$ trajetória da cultura jurídica moderna há um consenso de que áreas de investigação como História do Direito, História das Instituições Jurídicas e História das Idéias ou do Pensamento Jurídico, estão todas

8 Cf. José Honório Rodrigues, Filosofia e.... op. cit., p. 31-32.

9 Alberto Vivar Flores, Antropologia da Libertação Latino-Americana, São Paulo, Paulinas, 1991, p. 39.

10 Idem, ibidem. 
identificadas, ora com um saber formalista, abstrato e erudito, ora com uma verdade extraída de grandes textos legislativos, interpretações hexegéticas de magistrados, formulações herméticas de jusfilósofos e institutos arcai$\cos$ e burocratizados. Todavia, esta longa tradição foi interrompida nas últimas duas décadas por um renovado interesse de natureza críticoideológica por questões metodológicas sobre a História do Direito. Certamente que este "approch" reflete também o esgotamento de um certo tipo de historiografia jurídica embasada em valores liberal-individualistas. Esta retomada do viés historicista acerca das idéias ou das instituições jurídicas busca superar a demasiada crise que se abateu sobre este campo de pesquisa. A pouca relevância da disciplina não se deve à falta de especialistas ou aficcionados, mas muito mais em função de uma crise motivada por sua falta de significado e pela dificuldade de encontrar uma função que realmente justifique sua existência. ${ }^{11}$

Na verdade, uma análise mais atenta sobre as razões do exaurimento da História do Direito realça o fato de que a historiografia jurídica da modernidade. constituída em grande parte por princípios e valores liberaisburgueses, desempenham, no dizer de Antônio M. Hespanha, dois objetivos muitos claros:

a) primeiramente, "relativizar e, conseqüentemente, desvalorizar a ordem social e jurídica pré-burguesa, apresentando-a como fundada na irracionalidade, no preconceito e na justiça":

b) segundo, realizar "a apologia da luta da burguesia contra essa ordem ilegítima (Ancien Régime) e a favor da construção de um Direito e de uma sociedade 'naturais' e harmônicos, isto é, libertos da arbitrariedade e historicidade anteriores." ${ }^{12}$

Obviamente que a crítica burguesa empregada contra o antigo Direito e as organizações políticas feudais, gerou efeitos e foi eficaz num primeiro momento histórico, mas acabou perdendo significado com a edificação da ordem e da hegemonia liberal-individualista. Assim, a missão da historiografia tornou-se um instrumento de endeusamento da ordem jurídica,

11 Cf. Antônio M. Hespanha, A História do Direito na História Social, Lisboa, Livros Horizontes, s/d. p. 09.

12 Idem, ibidem.

R. Fac. Direito. Curitiba, a.28, n.28, 1994/95, p. 55-67 
política e social do modo de produção capitalista, na medida em que o espaço institucionalizado passa a ser coberto por um "universo ideológico apresentado como uma situação natural independente do dever histórico." ${ }^{13}$ Daí a historiografia jurídica presa aos textos legais e à exegese de seus corifeus orientar-se rumo, ora a um formalismo técnico-dogmático, ora a uma erudição antiquada da vida social.

Dessa forma, como salienta o lúcido investigador do Instituto de Ciências Sociais da Universidade de Lisboa, alguns juristas-historiadores declinaram por uma narrativa "conservadora e dogmática, que visava a 'justificação' da ordem social e jurídica vigente, tentando provar que ela mergulhava na 'tradição', no 'espírito nacional', ou que resultava num paulatino progresso do 'espírito humano'." ${ }^{14}$ Tal postura negligenciava toda e qualquer explicitação do Direito por um processo dinâmico, inserido no bojo de conflitos e tensões sociais. Outra tendência dos operadores do legalismo no meio acadêmico era a desconsideração por uma historicidade das instituições que possibilitasse, na formação dos juristas, a prática de condutas eficazes e legitimamente identificadas com os problemas da sociedade. Com isso favorecia-se a oficialização de uma historiografia "erudita e passadista que tendia a refugiar-se nas épocas históricas mais remotas" ${ }^{15}$ e em discussões meramente teórico-acadêmicas de cunho idealista/abstrato.

O surto do historicismo tradicional, ocultando-se no suposto mito da neutralidade do saber e da universalidade dos princípios da ciência positivista, expressão da fase concorrencial do Capitalismo, abnega o "problema crítico do conhecimento histórico" e ordena-se por uma perspectiva linear, estática e conservadora. Forja-se, assim, um conhecimento histórico elitista calcado na construção mútua da "neutralidade da cultura e dos intelectuais, (...) transformados numa espécie de instância arbitral colocada acima dos conceitos de classe. ${ }^{16}$

$\mathrm{Na}$ medida em que a historiografia tradicional (liberal-burguesa) passa a ser uma mera disciplina de justificação da ordem legal imperante e da acumulação de conhecimentos para a chamąda "cultura superior", sem

13 Antônio M. Hespanha, A História do Direito..., op. cit.

14 Antônio M. Hespanha, História das Instituições, Coimbra, Almedina, 1982.

15 Idem, ibidem.

16 Antônio M. Hespanha, A História do Direito..., op. cit., p. 12-13. 
fins úteis para com a realidade, a História do Direito perde sua significação e entra em um constante descrédito, constituindo-se num campo do saber de pouca utilidade, acabando, seus pressupostos, por sucumbir numa crise de eficácia. As profundas mudanças epistemológicas nas ciências humanas, os novos interesses, a insurgência de conflitos sociais e as recentes transformações por que vêm pașsando as formas de vida contemporânea determinam uma renovação metodológica nos estudos históricos das instituições jurídicas e políticas.

Desta feita, urge redefinir, na historicidade da crise, os novos marcos teórico-metodológicos que possibilitam alcançar um novo paradigma que envolva modalidades alternativas de interpretação, pesquisa e investigação histórica. Não mais uma historicidade linear, elitista e acumulativa, mas problematizante, desmistificadora e transformadora. Tendo em conta esse tipo de preocupação, importa refletir um pouco mais a questão das mudanças sociais, a crise dos paradigmas e os novos referenciais para se repensar a historicidade das idéias e das instituições no Direito.

\section{Novos marcos na historicidade do direito}

A renovação crítica na historiografia do Direito - no âmbito de suas fontes históricas, suas idéias e de suas instituições - começará a aparecer em fins dos anos sessenta e ao longo da década de setenta. ${ }^{17}$ Trata-se de substituir os modelos teóricos construídos de forma abstrata e dogmatizada, por investigações históricas, engendradas na dialética da produção e das relações sociais concretas. Sendo assim, há de se apontar que tipo de influências do pensamento filosófico e da teoria social contribuiu para que se repensasse quer a compreensão historicista do universo jurídico, quer o desenvolvimento crítico da historiografia do Direito.

Sem se ater a uma descrição pormenorizada e exaustiva, cabe assinalar cinco "eventos epistemológicos" que tiveram e ainda exercem uma significativa influência como marco de referência aos novos estudos históricos do Direito na América Latina. A titulo exemplificativo começa-

R. Fac. Direito, Curitiba, a.28, n.28, 1994/95, p. 55-67 
se com o registro dos três primeiros "eventos", também já mencionados pelo jurista historiador Antônio M. Hespanha.

a) O primeiro deles é a emergência, principalmente na Europa Ocidental, no final da década de sessenta, de uma corrente progressista de cunho neomarxista, que desencadeou profundas mudanças na teoria social em geral. Escreve Antônio M. Hespanha, a esse propósito, que a "renovação dos estudos marxistas, possibilitada politicamente pelo fim da guerra fria, consistiu na revaloração dos textos clássicos e na descoberta das potencialidades teóricas da interpretação gramsciana do marxismo, mérito de G. Della Volpe e de L. Althusser e suas escolas." 18 A retomada dos escritos de A. Gramsci propiciava o deslocamento do dogmatismo e do mecanicismo leninista para uma política cultural mais flexível e aberta à autocrítica. Já Louis Althusser parte da desconstrução estruturalista e economicista para lançar as bases epistemológicas de uma ciência "pura" do marxismo. O aumento do debate sobre a teoria marxista, bem como o amplo alcance de uma revisão necessária de seus cânones, coincidiu com a explosão do movimento de 68 , cuja manifestação mais intensa foi o movimento estudantil de 68 que, imbuído por uma estratégia antiimperialista e anticapitalista, trouxe consigo o discurso dos "novos sujeitos sociais e os novos conteúdos da revolução", materializando a crítica ideológica da ciência, das instituições e da divisão social do trabalho. ${ }^{19}$ Sob o ângulo da Historiografia, uma contribuição importante foi a reação à filosofia analítica por parte do marxismo britânico, representado por teóricos como E. Hobsbawm, C. Hill e E. P. Thompson, no sentido de discutir e fundar uma historiografia social.

b) Outro "evento epistemológico" é a proposta de uma "teoria crítica" de inspiração neo-marxista-freudiana representada pela Escola de Frankfurt e tendo como ideólogos T. Adorno, M. Horkheimer, H. Marcuse J. Habermas. A grande contribuição da escola alemã é propor uma filosofia histórico-social que possibilite a mudança da sociedade a partir da constituição de um novo tipo de homem. De um homem emancipado de sua

18 Antônio M. Hespanha, A História do Direito..., op. it., p. 14-15.

19 Cf. Otto Kallscheuer, Marxismo e Teorias do Conhecimento, In: Eric I. Hosbawm (org.), História do Marxismo. O Marxismo Hoje. Segunda Parte, Rio de Janeiro, Paz e Terra, 1989. v. 12. p. 14-15, 17, Perry Anderson, Considerações sobre o Marxismo Ocidental, Porto, Afrontamento, s/d. 
condição de alienado, da sua reconciliação com a natureza não-repressora e com o processo histórico por ele montado. A meta de alcance utópico está na reconciliação entre o sujeito social, a natureza não-repressora e a história. ${ }^{20}$ Naturalmente, a teoria crítica revela-se como um instrumental operante que permite a tomada de consciência dos sujeitos na história e a ruptura de sua condição de opressão, espoliação e marginalidade. Além desse aspecto relevante da teoria crítica enquanto processo adequado ao esclarecimento e à emancipação, recuperando todo um conteúdo utópicolibertador do pensamento ocidental, destaca-se, igualmente, como contundente "crítica dos grandes mitos da 'objetividade' da filosofia burguesa, nomeadamente, o positivismo e o neopositivismo." ${ }^{21}$ Sendo assim, para efeito de uma filosofia da História é, de um lado, a afirmação da "validade teórica do subjetivismo e do idealismo 'humanistas'", de outro, sob o aspecto prático, "traz para a experiência da investigação histórica novos domínios da realidade humana e social, com o que se abrem novos problemas e se exigem novas sínteses explicativas." 22

c) O terceiro referencial para se tomar em conta como contribuição à renovação da historiografia ocidental (particularmente da periferia) é o conjunto de critérios de investigação e análise posto pela Escola francesa dos "Annales". Um recorte bem delineado de seus traços é delineado na apresentação da obra coletiva publicada, na França, em 1980, no Magazine Littéraire:

"Gerada pelo grupo que dirigiu a revista francesa Annales - que teve como figuras centrais Lucien Febvre, Marc Bloch e Fernand Braudel -, a chamada Nova História sofreu um grande impulso nos últimos quinze anos, a ponto de se tornar a expressão mais característica da historiografia francesa dos nossos dias.

De facto, em França (e não só), a história das mentalidades, a história-problema vieram ocupar o espaço da história-relato. O próprio facto histórico - durante tanto tempo um valor seguro da ciência positivista

20 Antônio Carlos Wolkmer, Introdução ao Pensamento Juridico Crítico, São Paulo. Acadêmica, 1991, p. 39-40.

21 Antônio M. Hespanha, A História do Direito..., op. cit., p. 15.

22 Idem, ibidem.

R. Fac. Direito, Curitiba, a.28, n.28, 1994/95, p. 55-67 
- passou a ser um material como qualquer outro, tal como no caso da Economia Política, da Lingüística, da Demografia ou da Psicanálise." 23

Na verdade, desconstrói-se liames do paradigma tradicional da narrativa histórica, envolto na complexidade de grandes estruturas explicativas isoladas, marcadas ora por um idealismo eclético, ora por um mecanicismo cientificista, optando-se, agora, por uma História que interrelaciona os diversos significados da atividade humana. Deste modo, a renovação da História sob o aspecto da "significação" interdisciplinar proposta pela Escola dos "Annales", objetiva, segundo o preciso esclarecimento de Antônio M. Hespanha:

a) ultrapassar o positivismo histórico, inclinado "para a pura descrição de fatos isolados (...), através de um esforço no sentido de surpreender as estruturas mais profundas e mais estáveis (estruturas demográficas, econômicas, culturais, lingüísticas, etc.) que explicam a verificação e o encadeamento desses fatos";

b) eliminar os obstáculos "que se levantam entre os diversos setores especializados da história (...) de modo a estabelecer uma história global, restaurando a unidade real da vida (...)";

c) buscar uma História Social que "se socorra dos resultados das ciências humanas (sociologia, lingüística, economia, semiologia) ...";

d) finalmente, ter em conta a "história não só como ciência do passado (...), mas como ciência do presente, na medida em que, em ligação com as ciências humanas, investiga as leis de organização e transformação das sociedades humanas." 24

Transpondo esses pressupostos da "Nova História" para o campo das fontes, das idéias e das instituições jurídicas, chega-se à proposta de alinhamento de um modelo metodológico que venha redefinir as funções dos estudos históricos no âmbito do Direito. Tal postura implica na adesão a uma estratégia interdisciplinar, não uma interdisciplinariedade meramente

23 Jacques Le Goff, Emmanuel Le Roy Ladurie, et. alii. História e Nova História, Lisboa, Teorema, 1986, p. 5, Para um panorama geral da Escola francesa, ver: Peter Burke, $A$

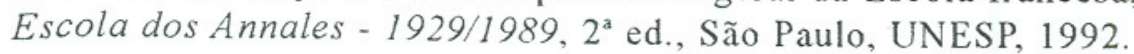

24 Antônio M. Hespanha, História..., op. cit., p. 17. 
formal, mas que tenha presente a crítica e a transformação do conteúdo problematizado.

Se os três primeiros fatores - emergência do neomarxismo, da teoria crítica e da "Nova História" - desempenharam uma grande motivação e avanços na historiografia ocidental, importa consignar outros dois movimentos que poderão exercer uma incisiva contribuição para os estudos histórico-jurídicos na América Latina, qual seja, o pensamento filosófico da libertação e a corrente brasileira do direito alternativo.

d) A quarta "linha de força" é a existência de um pensamento libertador latino-americano que se define por um luta teórico-prática contra uma situação sócio-política de dominação, opressão, exploração e injustiça. É o combate à plena adversidade e a busca incontida por mudanças radicais. Algumas formulações teóricas têm desempenhado uma função essencial no desenvolvimento do 'pensamento libertador' florescente na América Latina, tais como, a teoria da dependência (vertente econômica/política: T. dos Santos, F. H. Cardoso, Ruy M. Marini, A. Gunder Frank, Aníbal Quijano, P. González Casanova), a teologia da libertação (G. Gutierrez, L. Boff, H. Assman), a pedagogia libertadora do oprimido (Paulo Freire) e a filosofia da libertação (E. Dussel, J. C. Scannone, Rodolfo Kusch, Arturo A. Roig, etc). ${ }^{25}$

Ademais, como escreve corretamente David S. Rúbio, múltiplas devem ser consideradas as matrizes "condicionantes deste 'boom' libertador. Desde o peculiar fenômeno do populismo latino-americano, espécie de simulada alternativa às vias capitalista e socialista. Passando pelos acontecimentos históricos tão significativos como a Revolução Cubana, a Guerra Fria, os efeitos do processo descolonizador dos povos do Terceiro Mundo, até a influência de figuras vinculadas diretamente com a arena política e social do porte de Camilo Torres, Fidel Castro, Salvador Allende, Frantz Fanon, Velasco Alvorado e Che Guevara." 26

25 Consultar neste sentido: David Sanchez Rúbio, Proyección Juridica de la Filosofía Latino-americana de la Liberación. Aproximación Concreta a la Obra de Leopoldo Zea y Enrique Dussel, Tese de Doutoramento apresentada na Universidade de Sevilha, 01.12.94, p. 7, Horácio Ceruti Guldberg, Filosofia de la Liberación Latino-americana, México, Fondo de Cultura Económica, 1983, Frantz Fanon, Os Condenados da Terra, $2^{a}$ ed., Rio de Janeiro, Civilização Brasileira, 1979.

R. Fac. Direito, Curitiba, a.28, n.28, 1994/95, p.55-67 
O que se deve destacar, como tributo do "pensamento libertador" latino-americano para uma nova historicidade das formas de controle legal e de normatividade social, é a afirmação de uma alteridade emancipadora, mediante um Direito, livre da injustiça e da coerção, composta por sujeitos-cidadãos autênticos. Introduz-se, assim, na pesquisa histórica, os conceitos de "alteridade", "libertação" e "justiça social".

e) Por último, a presença mais recente e polêmica do movimento brasileiro designado de "direito alternativo". Não se trata rigorosamente de uma escola homogênea, com uma proposta acabada, mas muito mais de uma corrente que emerge, no final dos anos oitenta e início dos noventa, por parte de alguns magistrados (juizes gaúchos da AJURIS, como Amilton B. de Carvalho) e de professores universitários (Edmundo L. Arruda Jr., Roberto A. R. de Aguiar, José Geraldo de Souza Jr., etc). Implica na estratégia de luta dentro da legalidade instituída (no âmbito dos aparatos institucionalizados) e da legalidade a instituir (esfera da pluralidade dos grupos e movimentos sociais que têm seus direitos negados e reprimidos). Explora-se as fissuras e deficiências da ordem jurídica formal-individualista, buscando recuperar (através de uma interpretação crítica e uma aplicação humanista dos textos legais) a dimensão transformadora do Direito pondo-o a serviço da libertação. ${ }^{2}$

Ainda que não se tenha uma elaboração sistematizada e definitiva de suas características, alguns critérios podem ser registrados, em função da proposta teórica de seus fundadores (Amilton B. de Carvalho, Edmundo L. de Arruda Jr.). Senão, veja-se:

a) o Direito é um instrumento de luta a favor dos menos favorecidos e injustiçados;

b) rejeita-se a neutralidade e apoliticidade dos agentes e das instâncias de jurisdição;

c) busca-se construir uma sociedade socialista e democrática; dialético;

d) opção metodológica por um instrumental histórico-social

27 Cf. Antônio Carlos Wolkmer, Introdução ao Pensamento Juridico Crítico, $2^{\mathrm{a}}$ ed., São Paulo, Acadêmica, 1995, p. 
e) privilegia-se a legitimidade das maiorias e a justiça social. ${ }^{28}$

Os efeitos inovadores da juridicidade alternativa podem perfeitamente contribuir para estabelecer novos parâmetros de fundamentação, conceituação e finalidade no estudo historiográfico das idéias e das instituições jurídicas.

Esses "eventos epistemológicos" aqui destacados revelam-se inesgotáveis subsídios para compor os novos referenciais metodológicos de uma interpretação crítica e interdisciplinar no estudo histórico das idéias e das instituições no campo do Direito.

Certamente que a meta é alcançar uma nova compreensão historicista que rompa com o culturalismo elitista e o dogmatismo positivista, permitindo que as múltiplas e diversas disciplinas históricas do Direito (História do Direito, História das Idéias e/ou do Pensamento Jurídico, História das Instituições) deixem de ter um sentido apologético e ilusório da ordem tradicional dominante, adquirindo um sentido desmistificador e libertário. Libertador da verdade engendrada pela prática social e sintonizado com o "dever histórico" radicado na realização humana. ${ }^{29}$ De um "dever histórico" em que o homem seja o ser privilegiado, seu significado maior, o real sujeito da história. Com isso descarta-se o falso modismo do "fim" da História e da "morte" do sujeito na história. Repensa-se num novo sujeito (sujeitos coletivos) como fonte de legitimação de uma nova historicidade normativa.

Enfim, para se fazer avançar uma nova concepção histórica das fontes, das idéias e das instituições jurídicas faz-se obrigatório rever criticamente as ações, os acontecimentos e as produções do passado no que tange às práticas de regulamentação e controle social.

28 Consultar neste sentido: Am ton B. Carvalho, Magistratura e Direito Alternativo, SP. Acadêmica, 1992. p. 85-96, Edmundo L. de Arruda Jr., Introdução à Sociologia Jurídica Alternativa, SP. Acadêmica, 1993, p. 115-142, Horácio Wanderlei Rodrigues, Ensino Juridico e Direito Alternativo. SP., Acadêmica, 1993, p. 151-167.

29 Cf. Antônio M. Hespanha, A História do Direito..., op. cit., p. 17-18.

R. Fac. Direito. Curitiba, a.28, n.28, 1994/95, p.55-67 